\title{
Infant Immune Response to Respiratory Viral Infections
}

\section{Heinonen, Santtu}

2019-08

Heinonen , S , Rodriguez-Fernandez , R , Diaz , A , Oliva Rodriguez-Pastor , S , Ramilo , O \& Mejias , A 2019 , ' Infant Immune Response to Respiratory Viral Infections ' , Immunology and Allergy Clinics of North America, vol. 39 , no. 3 , pp. 361-+ . https://doi.org/10.1016/j.iac.2019.03.005

http://hdl.handle.net/10138/318088

https://doi.org/10.1016/j.iac.2019.03.005

cc_by_nc_nd

acceptedVersion

Downloaded from Helda, University of Helsinki institutional repository.

This is an electronic reprint of the original article.

This reprint may differ from the original in pagination and typographic detail.

Please cite the original version. 


\section{Infant Immune Response to Respiratory Viral Infections}

Santtu Heinonen, $\mathrm{MD}, \mathrm{PhD}^{1}$, Rosa Rodriguez-Fernandez, $\mathrm{MD}, \mathrm{PhD}^{2}$, Alejandro Diaz, $\mathrm{MD}^{3,4}$, Octavio Ramilo, $\mathrm{MD}^{3,4}$, Asuncion Mejias, MD, PhD, $\mathrm{MsCS}^{3,4,5^{*}}$

${ }^{1}$ New Children's Hospital, Pediatric Research Center, University of Helsinki and Helsinki University Hospital, Helsinki, Finland; ${ }^{2}$ Instituto de Investigación Sanitaria Gregorio Marañón (IISGM), Madrid, Spain; ${ }^{3}$ Center for Vaccines and Immunity, The Research Institute at Nationwide Children's Hospital \& ${ }^{4}$ Division of Infectious Diseases, Department of Pediatrics, Nationwide Children's Hospital and The Ohio State Colleague of Medicine, Columbus, OH, USA;

${ }^{5}$ Departamento de Farmacologia y Pediatria, Facultad de Medicina de Malaga, Universidad de Malaga, Spain.

\section{Contact information:}

- Santtu Heinonen: santtu.heinonen@hus.fi; New Children's Hospital, P.O. Box 347, 00029 HUS, Helsinki, Finland

- Rosa Rodriguez-Fernandez: rrodriguezf.hgugm@salud.madrid.org; Department of Pediatrics Hospital Materno-Infantil Gregorio Marañón, Madrid, Spain, 28009

- Alejandro Diaz: Alejandro.Diaz@nationwidechildrens.org; Pediatric Infectious Diseases, Nationwide Children's Hospital; 700 Children's Drive; Columbus, OH 43205

- Octavio Ramilo: Octavio.Ramilo@nationwidechildrens.org; Center for Vaccines and Immunity, WA4021; The Research Institute at Nationwide Children's Hospital; 700 Children's Drive; Columbus, $\mathrm{OH} 43205$

- Asuncion Mejias* (corresponding author): Asuncion.Mejias@nationwidechildrens.org; Center for Vaccines and Immunity, WA4022; The Research Institute at Nationwide Children's Hospital; 700 Children's Drive; Columbus, OH 43205

Disclosures: AM and OR and have received research grants from Janssen. AM has received fees for participation in advisory boards from Janssen and lectures from Abbvie. OR has received fees for participation in advisory boards from Abbvie, HuMabs, Janssen, Medimmune, Merck and Regeneron, and lectures from Abbvie. RRF has received fees from participating in advisory boards and lectures from Abbvie. Those fees were not related to the research described in this manuscript.

Key words: RSV, rhinovirus, innate immunity, adaptive immune response 


\section{Key points}

- Infants have increased susceptibility to respiratory viral infections, with RSV and RV being the leading pathogens as they cause acute bronchiolitis and are associated with development of recurrent wheezing and asthma.

- Innate immune responses evolve during infancy and differ from that of adults including differences in pathogen recognition and weaker interferon responses that may explain increased susceptibility to viral infections.

- Young infants often lack immunological memory towards the invading pathogen and their adaptive immune responses are biased to tolerance promoting T regulatory and Th2 immune responses while Th1 immune responses are restrained.

- Infancy may represent a critical window when environmental exposures including viral respiratory infections may shape the remodeling of the airway and the function of the immune system explaining the association between early life RSV and RV infections and development of recurrent wheezing and asthma later in life. 


\section{Synopsis}

Of all respiratory viruses that cause disease during infancy, RSV and RV represent the leading pathogens causing acute disease (bronchiolitis) and are associated with the development of recurrent wheezing and asthma. The immune system in infants is still developing and several factors contribute to their increased susceptibility to viral infections. These factors include differences in pathogen detection, weaker interferon responses, lack of immunological memory towards the invading pathogen and Thelper cell responses balanced to promote tolerance (Treg and Th2 type responses) and restrain inflammation. All these aspects are reviewed here with a focus on RSV and RV infections. 


\section{INTRODUCTION}

Respiratory viral infections, represent the leading cause of hospitalization in infants and young children worldwide and the second cause of infant mortality, excluding the neonatal period $^{1}$. Of all respiratory viruses that affect young children, respiratory syncytial virus (RSV), followed by rhinovirus (RV), represent the two leading respiratory viral pathogens, both because of their implications with acute disease severity, but also because of their association with the development of reactive airway disease/asthma later in life ${ }^{2-4}$. By two years of age almost all children have been infected with RSV at least once, and almost all infants develop at least one RV infection in the first year of life 5,6 . In addition, in a substantial proportion of children who develop asthma, the disease originates early in life with episodes of RSV or RV, specially RV-C, induced wheezing. This risk is increased in infants born prematurely ${ }^{7-9}$ One possible explanation for why respiratory viral infections early in life might drive atopic disease, including asthma, is that the antiviral immune response in infants is markedly different from that in older children. Additionally, there is increasing evidence of the role of the microbiome and viral-bacterial interactions in modulating the host infant immune response during the acute disease and long-term respiratory mobidity ${ }^{10,11}$.

In this chapter, we will review the different components of the infant innate and adaptive immune response to both RSV and RV, their differences according to age, and their possible influence in long term lung morbidity.

\section{THE INNATE IMMUNE RESPONSE}

Innate immunity has a key role in orchestrating early responses to RSV and RV infections, providing an early, non-programmed first line of defense against these pathogens. The 
importance of innate immunity is critical in infants, in whom the immune system is still developing and often lack immunologic memory towards the invading pathogen. Impaired or dysregulated innate immune responses may lead to slow and inadequate viral clearance, enhanced pathology and greater disease severity during the acute disease, with possible longterm consequences. Further, innate immune responses drive the development of effective adaptive immunity. Consequently, impaired innate immune responses may lead to inadequate adaptive immune responses, poor immunological memory and recurrent infections. Different components of the innate immune response play a fundamental role against respiratory viral infections, including the respiratory epithelium, interferon and other cytokines and innate immune cells such as neutrophils, monocytes, natural killer (NK) and dendritic cells (DC).

\section{Respiratory epithelium and pathogen detection}

The mucosal barrier not only acts as a protective barrier that prevents the direct contact between respiratory viruses and the airway epithelial cells, but also has active antiinflammatory and immunomodulatory properties ${ }^{12,13}$. The respiratory epithelium serves as the target for the infecting virus and has an important role at inhibiting RSV or RV infections. It represents the source of the initial inflammatory response in which antimicrobial peptides ${ }^{14}$, surfactant ${ }^{15}$ and several cytokines and chemokines are released contributing to the recruitment of inflammatory cells ${ }^{12,13}$.

Respiratory viruses typically infect ciliated airway epithelial cells with different viruses having variable tropisms to different parts of respiratory tract. Specifically, RSV infects human airway epithelia cells via the apical surfaces ${ }^{16,17}$. Different receptors have been identified for RSV (F and G proteins) in epithelial cells including, TLR-4, CX3CR1, annexin or nucleolin ${ }^{16,18,19}$. 
RV also binds to respiratory epithelial cells via several receptors which are different depending on the RV species ${ }^{20}$. RV-A and RV-B bind to the intercellular adhesion molecule 1 (ICAM-1) receptor and low-density lipoprotein receptor (LDLR) while RV-C binds to the newly identified cadherin-related family member 3 receptor $(\mathrm{CDHR}-3)^{5-7}$. The attachment of RSV or RV to their receptors elicits an innate immune response that leads to airway inflammation and remodeling. Thus, the airway epithelial cells along with the resident immune cells including macrophages, dendritic cells (DCS) and innate lymphoid cells (ILCS) have critical role in pathogen detection and initiation of the immune response. These cells express pattern recognition receptors (PRRs) that bind to pathogen associated molecular patterns (PAMPs). Several PRRs are important in recognizing respiratory viruses including toll-like receptors (TLRs) TLR4, TLR3, TLR2/6, TLR7/8, TLR9 that are expressed on the cell surface, or retinoic acid inducible gene- I (RIG-I) and melanoma differentiation associated gene-5 (MDA-5) that are soluble intracellular PRRs located in the cell cytoplasm ${ }^{21-23}$. Although with contradictory results, possibly due to differences in the patient populations studied, single nucleotide polymorphisms (SNPs) in TLR genes, have been associated with increased risk and severity to both RSV (i.e, TLR-4, TLR-9) and RV (i.e TLR-8) respiratory tract infections in infants and young children, emphasizing the importance of these receptors ${ }^{24-30}$.

The nasopharyngeal microbiota seems to modulate both systemic and mucolal host responses to viral infections. In RSV infected infants, microbiota clusters enriched for $H$. influenzae and Pneumococcus were associated with increased disease severity, enhanced TLR signaling and overexpression of neutrophil and macrophage related transcripts ${ }^{31,32}$. Recently, transcriptional profiling of nasopharyngeal samples from infants with RSV showed similar 
strong innate and interferon dominated responses that were identified also in peripheral blood, while in RV infected infants the responses were not as strong as in RSV and differed between the nasopharyngeal and peripheral blood samples ${ }^{33}$.

\section{Interferon responses}

Of all cytokines and chemokines released during RSV or RV infection, interferons (INFs) are one of the best characterized because of their antiviral properties, and associated with the defense against these infections. There are three main types of IFNs:

(1). Type-I INFs, (INF $\alpha / \beta)$ have direct antiviral effects, inducing an antiviral state both in infected and uninfected cells through the expression of interferon induced genes (ISGs) ${ }^{34}$. INF$\alpha$ is produced by several cell types including airway epithelial cells, alveolar macrophages and monocytes, but at least in RSV infection, plasmacytoid dendritic cells (pDCs) appear to be the primary source of Type-I INF $\alpha^{35}$. Plasmacytoid DCs harvested ex-vivo from infants and young children with acute RSV infection had lower INF- $\alpha$ production capacity compared to adult pDCs

35. In addition, a recent birth cohort study showed that a predominant Th2, Th17 and Type-I IFN response in the respiratory mucosa in early life during acute RSV (but not RV) infection, was associated with an increased risk of wheezing during the first 2 years of life ${ }^{36}$. These data emphasize the important differences on immune responses to viral infections according to age and also to the specific respiratory virus.

(2). Type-II IFN (IFN- $\gamma)$, which in early innate responses to the infection is produced predominantly by natural killer (NK), natural killer T (NKT); and type I innate lymphoid cells (ILCs). Later, after development of antigen specific immunity the main source of INF- $\gamma$ are T cells including CD4+ Th1; and CD8+ cytotoxic T cells ${ }^{37}$. The association between type-II interferon 
responses and RSV disease severity has been shown in multiple studies. Initial studies in animal models and humans suggested that higher INF- $\nu$ responses were directly associated with the severity of the disease ${ }^{38-40}$. However, a growing body of evidence has shown that the INF response to RSV is dysregulated. Indeed, infants with more severe RSV disease -need for hospitalization, oxygen administration or need for mechanical ventilation-- had lower concentrations of nasal IFN- $\gamma$ and/or suboptimal expression of IFN-related genes in the systemic compartment independent of their atopic status ${ }^{41-46}$.

(3). Type III INF (INF- $\lambda$ ) or mucosal IFNs, are structurally and functionally similar to type-I INFs, although bind to a different receptor complex and control the infection locally, rather than systemically. Studies suggest, that the human airway epithelium mounts virus-specific immune responses that are likely to determine the subsequent systemic immune responses. Specifically, studies showed that the absence of epithelial released of IL-28A, IL-28B and IL-29-- which belong to the Type-III IFN family-- after RSV infection, may explained in part the inadequacy of systemic immunity to the virus ${ }^{47}$.

Nevertheless, as mentioned above, the importance of adequate INF responses in the defense against viral respiratory tract infections in infants are highlighted by several studies reporting associations between weaker INF responses, at the mucosal and systemic compartments, and increased disease severity in RSV infected infants ${ }^{43,44,48-50}$. It is not surprising that viruses have developed several ways to inhibit INF production such as the nonstructural proteins of RSV (NS1 and NS2), that inhibit the production of INF $\alpha / \beta^{51,52}$. In addition, defective IFN production has been implicated in the increased susceptibility to RV in patients 
with asthma, with deficient Type-I (IFN- $\beta$ ) and Type-III (IFN- $\lambda$ ) interferon responses that have been reported in human respiratory epithelial cells of patients with asthma ${ }^{53,54}$.

\section{Other cytokines}

Other cytokines mediating early local innate immune responses to RSV and RV respiratory infections include tumor necrosis factor (TNF)- $\alpha$, IL-1, IL-6, IL-9, IL-10, CXCL10 (IP-10), CXCL8 (IL8), CCL2 (MCP1), CCL3 (MIP-1 $\alpha$ ) or CCL5 (RANTES) among others ${ }^{55-58}$. In addition to their direct cellular effect at the site of infection, these cytokines act as potent chemoattractants activating and recruiting circulating immune cells such as neutrophils, natural killer (NK) cells and cytotoxic $T$ cells to the airway mucosa. These proinflammatory innate immune responses have been found in infants with symptomatic RV infection rather than in children with asymptomatic $\mathrm{RV}$ detection ${ }^{59-61}$. RV infection may also induce eosinophilic infiltration and activation within the airway, which correlates with changes in airway hyper-responsiveness, especially in patients with asthma. Eosinophil-released ribonucleases, neurotoxin and eosinophilic cationic protein, have antiviral properties suggesting an innate antiviral role of these cells during RV infection ${ }^{62}$. Until recently, it was postulated that severe RSV infection was associated with an exaggerated inflammatory response. Similar to IFN responses, there is a growing body of evidence suggesting that host innate immune responses are actually inadequately activated or even suppressed in infants with severe RSV disease ${ }^{63-67}$. In a recent study, investigators showed that infants with severe RSV infection had lower capacity to produce the pro-inflammatory cytokines TNF- $\alpha$, IL-6 and CXCL8 (IL-8) in whole blood after LPS stimulation when compared to children with milder RSV infection and with healthy age-matched healthy controls ${ }^{68}$. Another study conducted in previously healthy infants hospitalized with RSV (median age 2.6 months) or RV 
bronchiolitis (5.1 months), compared the concentrations of 29 different cytokines (Th1, Th2, Th17, pro-inflammatory cytokines, chemokines and growth factors) induced by these two respiratory viruses in nasal wash samples. The study showed that overall, infants with acute RSV infection mounted a more robust immune response and had higher cytokine concentrations than those with RV infection. Nevertheless, also in infants with RV infection the CDSS inversely correlated with MCP-1 and IL-1- $\alpha$ concentrations ${ }^{43}$. In another study, a number cytokines were measured in nasopharyngeal aspirates in young infants hospitalized with a first episode of wheezing, to determine their association with the development of recurrent wheezing. Of all cytokines measured, MIP-1 $\alpha$ demonstrated the strongest and independent association with recurrent wheezing during the first two years of life ${ }^{69}$.

\section{Innate Immune cells}

(a) Neutrophils: The most abundant cell type in airway secretions from infants with RSV and RV bronchiolitis are neutrophils ${ }^{70-74}$. It still remains unclear whether neutrophils have a protective role or if they contribute to immunopathogenesis of the disease. Neutrophils can limit viral replication and spread, as they are able to detect and destroy infected cells, but at the same time produce enzymes that may damage the surrounding tissues through neutrophil extracellular traps (NETs). Post mortem studies in infants who died with severe RSV infection showed influx of neutrophils and macrophages in lung tissues ${ }^{75}$. During acute RV infection, both blood and nasal neutrophils increase within the first 72 hours. The high presence of phagocytic cells and pro-inflammatory mediators involved in granulocyte regulation such as granulocyte colony stimulating factor and IL-8 correlate with the severity of RV symptoms, even during mild symptomatic illness ${ }^{70,71}$. In premature and full term infants with acute RSV 
infection, neutrophils seem to be the main source of IL-9 ${ }^{56}$, a pro-inflammatory cytokine associated with development of bronchial hyperresponsiveness and asthma ${ }^{76}$. It is possible that the damage induced by neutrophils during the vulnerable period of lung development in infants with acute RSV or RV infection, may play a role in asthma inception having long lasting consequences in lung development ${ }^{77}$.

(b) Eosinophils, mast cells and basophils: The role of eosinophils during RSV infection is still a matter of debate. Original studies suggested that eosinophilic degranulation in infants during acute RSV infection was associated with airway obstruction ${ }^{78}$. More recently, in vitro studies showed that eosinophils actually facilitated RSV clearance and infectivity ${ }^{79}$. On the other hand, RV infection may induce eosinophil infiltration and activation within the airway, which correlates with changes in airway hyper-responsiveness, especially in patients with asthma. Some eosinophil-released products such as ribonucleases, eosinophil-derived neurotoxin and eosinophilic cationic protein, have antiviral properties suggesting an innate antiviral role of these cells during RV infection ${ }^{62}$. On the other hand mast cells and basophils do not appear to play a role in $\mathrm{RV}$ pathogenesis as shown by no variations of histamine levels during symptomatic infection ${ }^{80}$.

(c) Monocytes, NK, and DCs: Alveolar macrophages are thought to express both, immunoregulatory and antigen-presenting capabilities during respiratory viral infections ${ }^{81}$. Macrophages can be also productively infected by RSV and RV as demonstrated by ex-vivo viral replication in these cells ${ }^{81,82}$. In peripheral blood, the number of monocytes increases during acute RSV infection regardless of disease severity. However, in infants with severe RSV infection requiring hospitalization the proportion of monocytes expressing low levels of HLA-DR is 
increased, suggesting that monocyte function might be impaired in the most severe forms of the disease 83,84 .

The numbers of DCs, NK cells and cytotoxic T cells increase in the respiratory tract during RSV infection, as they have an important role in controlling viral infections ${ }^{58,85}$. While pDCs are important producers of type I INF (INF $\alpha)$, conventional DCs (CDC) have an important role as antigen presenting cells and regulating $T$ cell responses but also activating NK cells. NK cells contribute to early innate immune response by providing early source of INF- $\gamma$, by activating $T$ cells and by direct cytotoxic killing of the infected cells ${ }^{86}$. Lung tissue from infants that died with severe RSV infection showed absence of NK cells and CD8+ T cells and extensive antigen load ${ }^{75}$. In peripheral blood, lower DC and NK cell numbers were observed in RSV infected children vs. healthy controls but the proportion of cells with activated phenotype increased during RSV infection ${ }^{58,87}$.

\section{ADAPTIVE IMMUNE RESPONSES}

\section{Humoral Immune Responses}

Infants have decreased antibody responses compared with adults, due in part to their immature/developing immune response with a limited B-cell repertoire and inefficient generation of somatic hypermutations, and the presence of maternal antibodies which may interfere with viral-induced immunogenicity ${ }^{88-92}$. These issues are especially challenging when dealing with RSV, which typically causes severe disease in infants at a very young age -- the first 2-3 months of life--. On the other hand, RV induces genotype-specific neutralizing antibodies, with little cross-neutralization among the more than 100 genotypes. In addition, the genetic 
diversity of RV is continuously changing, hence favoring frequent infections that are caused by different genotypes.

(1) Antibody responses to RSV: In neonates, circulating RSV IgG antibodies, which are of maternal origin, significantly decrease by $\sim 4$ months of age, with an estimated half-life of 30-72 days ${ }^{90,93-95}$. The interference between pre-existing maternal antibodies and the infant antibody production after acute RSV infection has been shown by studies conducted in different patient populations. Those studies showed that levels of preexisting maternally transferred antibodies, and not age, was the most important factor influencing subsequent antibody responses in infants with RSV infection ${ }^{90,96}$. In addition, antibody responses are possibly influenced by other factors, such as disease severity or age, both associated with impaired interferon responses, that must be activated to promote adequate T and B cell immunity ${ }^{97-100}$. Nevertheless, humoral immunity plays a fundamental role in preventing severe RSV disease, and may have implications for diminishing long-term pulmonary morbidity. The proof or principle that antibody responses are critical at preventing severe RSV disease have been demonstrated in multiple randomized clinical trials using monoclonal antibodies (mAb) against the RSV Fusion protein (palivizumab or motavizumab) ${ }^{101-105}$. In those studies, the use of prophylaxis using mAb was associate with a significant reduction in hospitalization rates for RSV lower respiratory tract infection (LRTI), indicating that enough concentrations of neutralizing antibodies could be protective. Importantly, studies conducted in animal models and the infant population, showed a significant decreased in the incidence of subsequent wheezing/lung morbidity in the group that received palivizumab ${ }^{106-111}$. Vaccination against RSV in the third trimester of pregnancy could also protect infants in the first months of life and could have long lasting implications ${ }^{112}$. 
(2) Antibody responses to RV: Humoral immune responses are important for the prevention of RV infections; however, the mechanisms of protection are not completely understood. Additional support for the importance of humoral immunity is derived from patients with primary humoral immune deficiencies who experience more frequent and severe RV infections ${ }^{113}$. Virus-specific antibodies, both IgA (in the upper airway) and serum IgG increase after approximately one week of the acute infection and have been detected up to one year after the infection ${ }^{80,114}$. Cumulative serum antibodies against different RVs develop with age in association with repeated infections. It appears that mucosal antibody responses have enhanced neutralizing activity as compared with systemic antibody responses ${ }^{115}$ which however, correlate with immunity and with reduced symptom severity ${ }^{116}$. Also, the presence of antibodies in upper respiratory samples is associated with protection from homologous RV infection and disease.

\section{Cellular Immune Responses}

T cells participate in controlling RSV and RV infection through the recognition of viral antigens, which trigger both cytotoxic and antibody-mediated immune responses.

- CD8 T cell responses: After innate immune responses are activated, most of the cells that migrate to the respiratory tract are cytotoxic lymphocytes or CD8+ T cells. Secretion of RANTES and IP-10 (CXCL10) by RV-infected epithelial cells, neutrophils and phagocytes promotes T cell chemotaxis ${ }^{80}$. CD8 $+\mathrm{T}$ cells play a key role in viral clearance, in fact $\mathrm{T}$ cell immunodeficiencies are associated with prolonged viral shedding and therefore associated with more severe disease ${ }^{91}$. In otherwise healthy infants transient lymphopenia is common and occurs during the first days of RSV or RV infection, when T-cells are migrating to the respiratory tract ${ }^{117}$. This 
kinetics inversely correlate with changes in bronchial hyper-responsiveness in the acute phase of the infection and revert to baseline during convalescence, suggesting that T cells contribute to lower respiratory tract symptoms. More profound lymphopenia has been associated with enhanced RSV disease severity and even mortality ${ }^{92}$. We found that symptomatic RV infection on otherwise healthy infants, induced a robust transcriptional signature characterized by overexpression of innate immunity, but marked under-expression of adaptive immunity genes, specifically those related with T-cell and cytotoxic/NK-cell pathways, which was more profound in patients with severe disease ${ }^{61}$. Whether this reflects a failure to mount an adequate response that leads to a more severe illness, or whether it represents a well-controlled early step in the host response that balances the excessive inflammation observed during the acute viral infection remains unclear.

- CD4 T cell responses: $\mathrm{CD}^{+} \mathrm{T}$ cells have an important role in orchestrating and mediating the immune response against respiratory viruses. After T-cell receptors are activated, CD4+ T-cells differentiate into specific CD4 T-helper cell subsets including: Th1, Th2, Th17, T-regs and T follicular helper (Tfh) cells, which are defined by their function and cytokine milieu.

- Th1 cells: are critical during the acute infection, and are mediated mainly by IFN- $\gamma^{88}$. Other cytokines involved in Th1 immune responses include: IL1, IL-2, IL-12, IL-18 and TNF- $\alpha$. As discussed previously, impaired type-II interferon responses in blood and respiratory samples have been associated with enhanced RSV disease severity ${ }^{43,44,92}$. Additionally, while IFN- $\gamma$ can inhibit IL-4 mediated allergic responses, it may contribute to early wheeze after RV infection (but not RSV) in predisposed infants with atopy ${ }^{118}$. 
- Th2 cells and their induced immune responses are defined by the production of IL-4, IL-5, IL-9, and IL-13 and involved in antibody production, class switching and also in eosinophilic responses. Studies suggest that a predominant Th2 response during acute RSV infection assessed by decreased IFN- $\gamma /$ IL-4 ratios are associated with both more severe disease and also development of persistent wheezing ${ }^{46,119-122}$. There are several factors that could explain persistent wheezing after RSV or RV LRTI, including short and long-term remodeling of the airway physiology and certainly in the airway immune response.

- Th17 cells: These CD4+ T helper cells are defined by the production of IL-17A/F and IL-22, playing an essential role in protection against extracellular pathogens, autoimmunity and also in the development of some forms of asthma ${ }^{123,124}$. These third type of CD4+ T cells are considered a bridge between innate and adaptive immunity and have different functions during RSV or RV infections including: exaggerated mucus production, enhancing Th2 responses, favoring lungs neutrophilic infiltration and modulating CD8+ T cell responses. ${ }^{125-128}$. Higher concentrations of IL-17 (but also IL-4 and IFN- $\gamma$ ) were associated with a decreased risk of hospitalization in infants with RSV or RV LRTI, suggesting that there is tremendous overlap on the cytokines responses elicited after respiratory viral infections needed to control virusinduced lung disease in infants ${ }^{41,129,130}$.

- T-regulatory cells (Tregs): Tregs are responsible for maintaining tissue homeostasis during the acute infection by facilitating viral clearance and avoiding an excessive innate (neutrophils and NK cells) and cellular immune response of both CD4 and CD8 cells ${ }^{125}$. The main cytokines associated with Tregs mediated responses are IL-10 and TGF- $\beta$, that play an important role in the delicate balance between Th1, Th2 and Th17 responses. ${ }^{88,91,131}$ IL-10 has important 
regulatory functions during acute and convalescent RSV and RV infection in infants. Some studies showed the association between increased concentrations of serum IL-10 and acute RSV or RV severity, as assessed by the need for supplemental O2 or viral-induced wheeze, while others have shown a protective effect of mucosal IL-10 in regards to need for oxygen and severity $^{92}$. Studies showed that while IL-12 favored the differentiation of CD4+ T cells into a Th1 phenotype, IL-10 inhibited Th1 responses, thus favoring a Th2 phenotype and development of subsequently wheezing ${ }^{132}$. Moreover, increased serum monocyte derived IL-10 responses one month after acute RSV infection have been associated with recurrent wheezing during the first year of life, emphasizing the important regulatory role of this cytokine ${ }^{121}$.

- T-follicular helper cells (Tfh): These recently identified CD4 T-cells are characterized by the expression of CXCR5 (chemokine receptor), BCL6 (transcription factor) and PD-1 (inhibitory molecule). Tfh-cells help with B-cell class switching and are essential for affinity maturation and the development of memory B-cells ${ }^{133,134}$. There is limited information about their role in infants with RSV or rhinovirus infection. A recent study in infants with either RSV or RV infection showed that activation of BCL6 pathways in blood or NP samples were associated with RSV but not RV severity ${ }^{135}$.

\section{AGE SPECIFIC DIFFERENCES IN IMMUNE RESPONSES}

The immune system in infant is immature and drastic changes in the composition and function of immune cells take place after birth, especially during the first months of life ${ }^{136,137}$. Environmental exposures seem to be key drivers in the development of the infant immune response. This suggests that infancy represents a critical window that shapes the function of the immune system and contributes to the remodeling of the airway for years to come, offering 
a potential explanation for the association between early life RSV and RV infections, and the subsequent development of reactive airway disease/asthma later in life. Different studies have shown quantitative and qualitative differences in PRR responses between infants (cord blood) and adults samples that may contribute to increased susceptibility to respiratory tract infections in young children. Stimulation assays with different TLR agonists showed that cord blood derived white blood cells (WBCs) produce equal or greater amounts of Th2 and Th17 type cytokines (e.g. IL-6; IL-10; and IL-23), but had weaker Th1 responses (INF $\alpha$ IFN- $\gamma$ ) when compared with adult WBCs ${ }^{138}$. In addition, weaker responses to lipopolysaccharide (LPS) were observed in cord blood derived monocytes, who also had lower TLR4 expression, compared with adult monocytes ${ }^{139}$. In addition, infants lack immunologic memory towards the invading pathogen. Maternal antibodies provide protection during the first months of life, but the protection is incomplete (especially against mucosal infections) and wanes after 4-6 months of age. Infant's immune response is geared towards T regulatory and CD4+ Th2 over Th1 responses. This balance may be beneficial in the development of tolerance to self and other antigens, but it may also increase the susceptibility to viral infections ${ }^{140}$. As pathogen detection is critical for the activation of the immune cascade, and as Th1 type responses are considered fundamental against intracellular pathogens including viruses, these age specific differences could explain in part the increased susceptibility to viral respiratory tract infections in infants. 


\section{HOST TRANSCRIPTIONAL PROFILING}

Host transcriptional profiling has provided valuable insights into immune responses in respiratory tract infections. Our group and others have showed that systemic immune response against RSV, RV or influenza respiratory tract infections is characterized by increased expression of neutrophil related genes and relative decreased expression of interferon, B and T cell related genes according to severity ${ }^{33,141-144}$. Importantly, the breadth and magnitude of those responses are different according to the respiratory viruses and are greatly influence by age. Preliminary studies in asymptomatic healthy infants showed that IFN and inflammation genes were underexpressed in young infants ( $<6$ months), suggesting that infants in early life may be uniquely susceptible to respiratory viral infections (data unpublished).

We showed that the immune transcriptional profiles of infants less than 6 months of age compared with those 6-24 months old were significantly different in response to RSV or rhinovirus infection, adjusted for disease severity and other demographic characteristics ${ }^{44}$. Overall, the immune profile of infants $<6$ months of age hospitalized with RSV LRTI was contracted and dominated by a greater proportion of underexpressed transcripts compared with that of older children (6-24 months), also hospitalized with RSV infection. Using a number of analytic strategies, including modular analyses --a data driven tool designed to group transcripts based on their biological function ${ }^{145}$-- we found that despite these infants being equally ill as reflected by their similar clinical disease severity scores, those of younger age displayed significantly less overexpression of interferon, inflammation and neutrophil transcripts, lack of activation of plasma cell related genes, and greater underexpression of Bcell, NK-cell and T-cell related genes (Figure 1A) ${ }^{44}$. Further, when comparing modular 
fingerprints from children hospitalized with LRTI due to RV, also stratified by age (less than 6 months versus 6-24 months of age), we found significant differences in the type and breadth of the immune responses to this viral infection. These changes in the immune response was observed in symptomatic RV infection while no changes in systemic gene expression was observed during asymptomatic viral detection ${ }^{146}$. Particularly, children with RV infection, independent of age, demonstrated mild activation of immune response related pathways, with more subtle differences according to age (Figure 1B). While younger infants with RV infection showed less activation of interferon related genes, there were no differences in the degree of overexpression of neutrophil, monocyte or inflammatory genes. On the other hand, and similar to that from infants with RSV LRTI, adaptive immune response pathways were greatly suppressed in younger versus older children with RV LRTI ${ }^{44}$.

These data suggest that although there are pathways that are commonly activated upon infection with different respiratory viruses, the type and breadth of these responses are greatly influenced by age. Nevertheless, whether age at the time of the infection and/or the observed age-related changes in immune responses influence the subsequent development of asthma or atopy awaits further study.

\section{SUMMARY}

Infancy represents a critical window when environmental exposures, and in particular RSV and $R V$ infections, may shape the remodeling of the airway and the function of a developing immune system. The immune response evolves during infancy and is characterized early on by lack immunologic memory towards the invading pathogen, and a biased tolerogenic immune response (Treg \& Th2 responses), while Th1 immunity is restrained. These specific nuances on 
the immune response, may explain the infant susceptibility to these infections and their association with the development of recurrent wheezing/asthma later in life. 


\section{BIBLIOGRAPHY}

1. Lozano R, Naghavi M, Foreman K, et al. Global and regional mortality from 235 causes of death for 20 age groups in 1990 and 2010: a systematic analysis for the Global Burden of Disease Study 2010. Lancet 2012;380:2095-128.

2. Jackson DJ, Gangnon RE, Evans MD, et al. Wheezing rhinovirus illnesses in early life predict asthma development in high-risk children. Am J Respir Crit Care Med 2008;178:667-72.

3. Sigurs N, Aljassim F, Kjellman B, et al. Asthma and allergy patterns over 18 years after severe RSV bronchiolitis in the first year of life. Thorax 2010;65:1045-52.

4. Stein RT, Sherrill D, Morgan WJ, et al. Respiratory syncytial virus in early life and risk of wheeze and allergy by age 13 years. Lancet 1999;354:541-5.

5. van der Zalm MM, Wilbrink B, van Ewijk BE, Overduin P, Wolfs TF, van der Ent CK. Highly frequent infections with human rhinovirus in healthy young children: a longitudinal cohort study. J Clin Virol 2011;52:317-20.

6. Mejias A, Ramilo O. New options in the treatment of respiratory syncytial virus disease. J Infect 2015;71 Suppl 1:S80-7.

7. Bonnelykke K, Coleman AT, Evans MD, et al. Cadherin-related Family Member 3 Genetics and Rhinovirus C Respiratory Illnesses. Am J Respir Crit Care Med 2018;197:589-94.

8. Miller EK, Bugna J, Libster $\mathrm{R}$, et al. Human rhinoviruses in severe respiratory disease in very low birth weight infants. Pediatrics 2012;129:e60-7.

9. Drysdale SB, Alcazar M, Wilson T, et al. Respiratory outcome of prematurely born infants following human rhinovirus $A$ and $C$ infections. Eur J Pediatr 2014;173:913-9.

10. Beigelman A, Bacharier LB. Early-life respiratory infections and asthma development: role in disease pathogenesis and potential targets for disease prevention. Curr Opin Allergy Clin Immunol 2016;16:172-8.

11. de Steenhuijsen Piters WA, Heinonen S, Hasrat R, et al. Nasopharyngeal Microbiota, Host Transcriptome, and Disease Severity in Children with Respiratory Syncytial Virus Infection. Am J Respir Crit Care Med 2016;194:1104-15.

12. Li Y, Dinwiddie DL, Harrod KS, Jiang Y, Kim KC. Anti-inflammatory effect of MUC1 during respiratory syncytial virus infection of lung epithelial cells in vitro. Am J Physiol Lung Cell Mol Physiol 2010;298:L558-63.

13. Zanin M, Baviskar P, Webster R, Webby R. The Interaction between Respiratory Pathogens and Mucus. Cell Host Microbe 2016;19:159-68.

14. Currie SM, Gwyer Findlay E, McFarlane AJ, et al. Cathelicidins Have Direct Antiviral Activity against Respiratory Syncytial Virus In Vitro and Protective Function In Vivo in Mice and Humans. J Immunol 2016;196:2699-710.

15. LeVine AM, Elliott J, Whitsett JA, et al. Surfactant protein-d enhances phagocytosis and pulmonary clearance of respiratory syncytial virus. Am J Respir Cell Mol Biol 2004;31:193-9.

16. Johnson SM, McNally BA, loannidis I, et al. Respiratory Syncytial Virus Uses CX3CR1 as a Receptor on Primary Human Airway Epithelial Cultures. PLoS Pathog 2015;11:e1005318.

17. Guo-Parke H, Canning P, Douglas I, et al. Relative respiratory syncytial virus cytopathogenesis in upper and lower respiratory tract epithelium. Am J Respir Crit Care Med 2013;188:842-51.

18. Griffiths C, Drews SJ, Marchant DJ. Respiratory Syncytial Virus: Infection, Detection, and New Options for Prevention and Treatment. Clin Microbiol Rev 2017;30:277-319.

19. Tayyari F, Marchant D, Moraes TJ, Duan W, Mastrangelo P, Hegele RG. Identification of nucleolin as a cellular receptor for human respiratory syncytial virus. Nat Med 2011;17:1132-5.

20. Drysdale SB, Mejias A, Ramilo O. Rhinovirus - not just the common cold. J Infect 2017;74 Suppl 1:S41-S6. 
21. Kurt-Jones EA, Popova L, Kwinn L, et al. Pattern recognition receptors TLR4 and CD14 mediate response to respiratory syncytial virus. Nat Immunol 2000;1:398-401.

22. Takeuchi O, Akira S. Innate immunity to virus infection. Immunol Rev 2009;227:75-86.

23. Marr N, Turvey SE, Grandvaux N. Pathogen recognition receptor crosstalk in respiratory syncytial virus sensing: a host and cell type perspective. Trends Microbiol 2013;21:568-74.

24. Janssen R, Bont L, Siezen CLE, et al. Genetic susceptibility to respiratory syncytial virus bronchiolitis is predominantly associated with innate immune genes. J Infect Dis 2007;196:826-34.

25. Helminen $M$, Nuolivirta K, Virta $M$, et al. IL-10 gene polymorphism at -1082 A/G is associated with severe rhinovirus bronchiolitis in infants. Pediatr Pulmonol 2008;43:391-5.

26. Miyairi I, DeVincenzo JP. Human genetic factors and respiratory syncytial virus disease severity. Clin Microbiol Rev 2008;21:686-703.

27. Toivonen L, Vuononvirta J, Mertsola J, Waris M, He Q, Peltola V. Polymorphisms of Mannosebinding Lectin and Toll-like Receptors 2, 3, 4, 7 and 8 and the Risk of Respiratory Infections and Acute Otitis Media in Children. Pediatr Infect Dis J 2017;36:e114-e22.

28. Alvarez AE, Marson FAL, Bertuzzo CS, et al. Association between single nucleotide polymorphisms in TLR4, TLR2, TLR9, VDR, NOS2 and CCL5 genes with acute viral bronchiolitis. Gene 2018;645:7-17.

29. Zhou J, Zhang X, Liu S, et al. Genetic association of TLR4 Asp299Gly, TLR4 Thr399lle, and CD14 C159T polymorphisms with the risk of severe RSV infection: a meta-analysis. Influenza Other Respir Viruses 2016;10:224-33.

30. Halfhide CP, Brearey SP, Flanagan BF, et al. Neutrophil TLR4 expression is reduced in the airways of infants with severe bronchiolitis. Thorax 2009;64:798-805.

31. de Steenhuijsen Piters WAA, Heinonen S, Hasrat R, et al. Nasopharyngeal Microbiota, Host Transcriptome, and Disease Severity in Children with Respiratory Syncytial Virus Infection. Am J Respir Crit Care Med 2016;194:1104-15.

32. Rosas-Salazar C, Shilts MH, Tovchigrechko A, et al. Differences in the Nasopharyngeal Microbiome During Acute Respiratory Tract Infection With Human Rhinovirus and Respiratory Syncytial Virus in Infancy. J Infect Dis 2016;214:1924-8.

33. Do LAH, Pellet J, van Doorn HR, et al. Host Transcription Profile in Nasal Epithelium and Whole Blood of Hospitalized Children Under 2 Years of Age With Respiratory Syncytial Virus Infection. J Infect Dis 2017;217:134-46.

34. McNab F, Mayer-Barber K, Sher A, Wack A, O'Garra A. Type I interferons in infectious disease. Nat Rev Immunol 2015;15:87-103.

35. Marr N, Wang T-I, Kam SHY, et al. Attenuation of respiratory syncytial virus-induced and RIG-Idependent type I IFN responses in human neonates and very young children. J Immunol 2014;192:948-

57.

36. Turi KN, Shankar J, Anderson LJ, et al. Infant Viral Respiratory Infection Nasal Immune-Response Patterns and Their Association with Subsequent Childhood Recurrent Wheeze. Am J Respir Crit Care Med 2018;198:1064-73.

37. Schoenborn JR, Wilson CB. Regulation of Interferon- $\gamma$ During Innate and Adaptive Immune Responses. Advances in Immunology: Academic Press; 2007:41-101.

38. van Schaik SM, Tristram DA, Nagpal IS, Hintz KM, Welliver RC, 2nd, Welliver RC. Increased production of IFN-gamma and cysteinyl leukotrienes in virus-induced wheezing. J Allergy Clin Immunol 1999;103:630-6.

39. van Schaik SM, Obot N, Enhorning $\mathrm{G}$, et al. Role of interferon gamma in the pathogenesis of primary respiratory syncytial virus infection in BALB/c mice. J Med Virol 2000;62:257-66. 
40. Jafri HS, Chavez-Bueno S, Mejias A, et al. Respiratory syncytial virus induces pneumonia, cytokine response, airway obstruction, and chronic inflammatory infiltrates associated with long-term airway hyperresponsiveness in mice. J Infect Dis 2004;189:1856-65.

41. Nicholson EG, Schlegel C, Garofalo RP, et al. Robust Cytokine and Chemokine Response in Nasopharyngeal Secretions: Association With Decreased Severity in Children With Physician Diagnosed Bronchiolitis. J Infect Dis 2016;214:649-55.

42. Piedra FA, Mei M, Avadhanula V, et al. The interdependencies of viral load, the innate immune response, and clinical outcome in children presenting to the emergency department with respiratory syncytial virus-associated bronchiolitis. PLoS One 2017;12:e0172953.

43. Garcia C, Soriano-Fallas A, Lozano J, et al. Decreased innate immune cytokine responses correlate with disease severity in children with respiratory syncytial virus and human rhinovirus bronchiolitis. Pediatr Infect Dis J 2012;31:86-9.

44. Mejias A, Dimo B, Suarez NM, et al. Whole blood gene expression profiles to assess pathogenesis and disease severity in infants with respiratory syncytial virus infection. PLoS Med 2013;10:e1001549.

45. Bont L, Heijnen CJ, Kavelaars A, et al. Local interferon-gamma levels during respiratory syncytial virus lower respiratory tract infection are associated with disease severity. Journal of Infectious Diseases 2001;184:355-8.

46. Joshi P, Shaw A, Kakakios A, Isaacs D. Interferon-gamma levels in nasopharyngeal secretions of infants with respiratory syncytial virus and other respiratory viral infections. Clin Exp Immunol 2003;131:143-7.

47. Ioannidis I, McNally B, Willette $M$, et al. Plasticity and virus specificity of the airway epithelial cell immune response during respiratory virus infection. J Virol 2012;86:5422-36.

48. Aberle JH, Aberle SW, Dworzak MN, et al. Reduced Interferon- $\gamma$ Expression in Peripheral Blood Mononuclear Cells of Infants with Severe Respiratory Syncytial Virus Disease. Am J Respir Crit Care Med 1999;160:1263-8.

49. Bont L, Heijnen CJ, Kavelaars A, et al. Local Interferon- $\gamma$ Levels during Respiratory Syncytial Virus Lower Respiratory Tract Infection Are Associated with Disease Severity. J Infect Dis 2001;184:355-8.

50. Piedra F-A, Mei M, Avadhanula $V$, et al. The interdependencies of viral load, the innate immune response, and clinical outcome in children presenting to the emergency department with respiratory syncytial virus-associated bronchiolitis. PLoS One 2017;12:e0172953.

51. Ramaswamy M, Shi L, Monick MM, Hunninghake GW, Look DC. Specific inhibition of type I interferon signal transduction by respiratory syncytial virus. Am J Respir Cell Mol Biol 2004;30:893-900.

52. Lo MS, Brazas RM, Holtzman MJ. Respiratory syncytial virus nonstructural proteins NS1 and NS2 mediate inhibition of Stat2 expression and alpha/beta interferon responsiveness. J Virol 2005;79:9315-9.

53. Wark PA, Johnston SL, Bucchieri F, et al. Asthmatic bronchial epithelial cells have a deficient innate immune response to infection with rhinovirus. J Exp Med 2005;201:937-47.

54. Contoli M, Message SD, Laza-Stanca V, et al. Role of deficient type III interferon-lambda production in asthma exacerbations. Nature medicine 2006;12:1023-6.

55. Sheeran P, Jafri H, Carubelli C, et al. Elevated cytokine concentrations in the nasopharyngeal and tracheal secretions of children with respiratory syncytial virus disease. Pediatr Infect Dis J 1999;18:115-

22.

56. McNamara PS, Flanagan BF, Baldwin LM, Newland P, Hart CA, Smyth RL. Interleukin 9 production in the lungs of infants with severe respiratory syncytial virus bronchiolitis. Lancet 2004;363:1031-7.

57. McNamara PS, Flanagan BF, Hart CA, Smyth RL. Production of chemokines in the lungs of infants with severe respiratory syncytial virus bronchiolitis. J Infect Dis 2005;191:1225-32. 
58. Kerrin A, Fitch P, Errington C, et al. Differential lower airway dendritic cell patterns may reveal distinct endotypes of RSV bronchiolitis. Thorax 2017;72:620-7.

59. Naclerio RM, Proud D, Lichtenstein LM, et al. Kinins are generated during experimental rhinovirus colds. J Infect Dis 1988;157:133-42.

60. Proud D, Naclerio RM, Gwaltney JM, Hendley JO. Kinins are generated in nasal secretions during natural rhinovirus colds. J Infect Dis 1990;161:120-3.

61. Heinonen S, Jartti T, Garcia C, et al. Rhinovirus Detection in Symptomatic and Asymptomatic Children: Value of Host Transcriptome Analysis. Am J Respir Crit Care Med 2016;193:772-82.

62. Rosenberg HF, Domachowske JB. Eosinophils, eosinophil ribonucleases, and their role in host defense against respiratory virus pathogens. Journal of leukocyte biology 2001;70:691-8.

63. Laham FR, Trott AA, Bennett BL, et al. LDH concentration in nasal-wash fluid as a biochemical predictor of bronchiolitis severity. Pediatrics 2010;125:e225-33.

64. Bennett BL, Garofalo RP, Cron SG, et al. Immunopathogenesis of respiratory syncytial virus bronchiolitis. J Infect Dis 2007;195:1532-40.

65. Larranaga CL, Ampuero SL, Luchsinger VF, et al. Impaired immune response in severe human lower tract respiratory infection by respiratory syncytial virus. Pediatr Infect Dis J 2009;28:867-73.

66. Mansbach JM, Piedra PA, Laham FR, et al. Nasopharyngeal lactate dehydrogenase concentrations predict bronchiolitis severity in a prospective multicenter emergency department study. Pediatr Infect Dis J 2012;31:767-9.

67. Welliver TP, Garofalo RP, Hosakote Y, et al. Severe human lower respiratory tract illness caused by respiratory syncytial virus and influenza virus is characterized by the absence of pulmonary cytotoxic lymphocyte responses. J Infect Dis 2007;195:1126-36.

68. Mella C, Suarez-Arrabal MC, Lopez S, et al. Innate immune dysfunction is associated with enhanced disease severity in infants with severe respiratory syncytial virus bronchiolitis. J Infect Dis 2013;207:564-73.

69. Sugai K, Kimura H, Miyaji Y, et al. MIP-1alpha level in nasopharyngeal aspirates at the first wheezing episode predicts recurrent wheezing. J Allergy Clin Immunol 2016;137:774-81.

70. Turner RB, Weingand KW, Yeh CH, Leedy DW. Association between interleukin-8 concentration in nasal secretions and severity of symptoms of experimental rhinovirus colds. Clin Infect Dis 1998;26:840-6.

71. Turner RB. The role of neutrophils in the pathogenesis of rhinovirus infections. Pediatr Infect Dis J 1990;9:832-5.

72. Sheeran P, Jafri H, Carubelli C, et al. Elevated cytokine concentrations in the nasopharyngeal and tracheal secretions of children with respiratory syncytial virus disease. Pediatr Infect Dis J 1999;18:115-

22.

73. McNamara PS, Ritson P, Selby A, Hart CA, Smyth RL. Bronchoalveolar lavage cellularity in infants with severe respiratory syncytial virus bronchiolitis. Arch Dis Child 2003;88:922-6.

74. Smith PK, Wang SZ, Dowling KD, Forsyth KD. Leucocyte populations in respiratory syncytial virusinduced bronchiolitis. J Paediatr Child Health 2001;37:146-51.

75. Welliver TP, Garofalo RP, Hosakote Y, et al. Severe human lower respiratory tract illness caused by respiratory syncytial virus and influenza virus is characterized by the absence of pulmonary cytotoxic lymphocyte responses. J Infect Dis 2007;195:1126-36.

76. Kearley J, Erjefalt JS, Andersson C, et al. IL-9 governs allergen-induced mast cell numbers in the lung and chronic remodeling of the airways. Am J Respir Crit Care Med 2011;183:865-75.

77. Geerdink RJ, Pillay J, Meyaard L, Bont L. Neutrophils in respiratory syncytial virus infection: A target for asthma prevention. J Allergy Clin Immunol 2015;136:838-47.

78. Garofalo R, Kimpen JL, Welliver RC, Ogra PL. Eosinophil degranulation in the respiratory tract during naturally acquired respiratory syncytial virus infection. J Pediatr 1992;120:28-32. 
79. Rosenberg HF, Dyer KD, Domachowske JB. Eosinophils and their interactions with respiratory virus pathogens. Immunol Res 2009;43:128-37.

80. Jacobs SE, Lamson DM, St George K, Walsh TJ. Human rhinoviruses. Clinical microbiology reviews 2013;26:135-62.

81. Midulla F, Villani A, Panuska JR, et al. Respiratory syncytial virus lung infection in infants: immunoregulatory role of infected alveolar macrophages. J Infect Dis 1993;168:1515-9.

82. Laza-Stanca V, Message SD, Edwards MR, et al. The role of IL-15 deficiency in the pathogenesis of virus-induced asthma exacerbations. PLoS Pathog 2011;7:e1002114.

83. Heinonen S, Lopez S, Ye F, et al. Robust innate immune responses correlate with improved clinical outcomes in infants with respiratory syncytial virus acute respiratory infection (Abstract). ESPID (European Society for Pediatric Infectious Diseases) Annual Meeting 2015; 2015 12-16.5.2015; Leipzig, Germany.

84. Ahout IM, Jans J, Haroutiounian L, et al. Reduced Expression of HLA-DR on Monocytes During Severe Respiratory Syncytial Virus Infections. Pediatr Infect Dis J 2016;35:e89-96.

85. Gill MA, Palucka AK, Barton T, et al. Mobilization of plasmacytoid and myeloid dendritic cells to mucosal sites in children with respiratory syncytial virus and other viral respiratory infections. J Infect Dis 2005;191:1105-15.

86. Culley FJ. Natural killer cells in infection and inflammation of the lung. Immunology 2009;128:151-63.

87. Larrañaga $\mathrm{CL}$, Ampuero SL, Luchsinger VF, et al. Impaired immune response in severe human lower tract respiratory infection by respiratory syncytial virus. Pediatr Infect Dis J 2009;28:867-73.

88. Ruckwardt TJ, Morabito KM, Graham BS. Determinants of early life immune responses to RSV infection. Curr Opin Virol 2016;16:151-7.

89. Murphy BR, Alling DW, Snyder MH, et al. Effect of age and preexisting antibody on serum antibody response of infants and children to the $F$ and $G$ glycoproteins during respiratory syncytial virus infection. J Clin Microbiol 1986;24:894-8.

90. Trento A, Rodriguez-Fernandez R, Gonzalez-Sanchez MI, et al. The Complexity of Antibody Responses Elicited against the Respiratory Syncytial Virus Glycoproteins in Hospitalized Children Younger than 2 Years. Front Microbiol 2017;8:2301.

91. Lambert L, Sagfors AM, Openshaw PJ, Culley FJ. Immunity to RSV in Early-Life. Front Immunol 2014;5:466.

92. Russell CD, Unger SA, Walton M, Schwarze J. The Human Immune Response to Respiratory Syncytial Virus Infection. Clin Microbiol Rev 2017;30:481-502.

93. Capella C, Chaiwatpongsakorn S, Gorrell E, et al. Prefusion F, Postfusion F, G Antibodies, and Disease Severity in Infants and Young Children With Acute Respiratory Syncytial Virus Infection. J Infect Dis 2017;216:1398-406.

94. Chu HY, Steinhoff MC, Magaret A, et al. Respiratory syncytial virus transplacental antibody transfer and kinetics in mother-infant pairs in Bangladesh. J Infect Dis 2014;210:1582-9.

95. Ochola R, Sande C, Fegan G, et al. The level and duration of RSV-specific maternal IgG in infants in Kilifi Kenya. PLoS One 2009;4:e8088.

96. Shinoff JJ, O'Brien KL, Thumar B, et al. Young infants can develop protective levels of neutralizing antibody after infection with respiratory syncytial virus. J Infect Dis 2008;198:1007-15.

97. Pulendran B, Ahmed R. Translating innate immunity into immunological memory: implications for vaccine development. Cell 2006;124:849-63.

98. Gans HA. The status of live viral vaccination in early life. Vaccine 2013;31:2531-7.

99. Kim D, Niewiesk S. Synergistic induction of interferon alpha through TLR-3 and TLR-9 agonists identifies CD21 as interferon alpha receptor for the B cell response. PLoS Pathog 2013;9:e1003233. 
100. Swanson CL, Wilson TJ, Strauch P, Colonna M, Pelanda R, Torres RM. Type I IFN enhances follicular B cell contribution to the T cell-independent antibody response. J Exp Med 2010;207:1485-500. 101. Palivizumab, a Humanized Respiratory Syncytial Virus Monoclonal Antibody, Reduces Hospitalization From Respiratory Syncytial Virus Infection in High-risk Infants. Pediatrics 1998;102:531-7. 102. Feltes TF, Cabalka AK, Meissner HC, et al. Palivizumab prophylaxis reduces hospitalization due to respiratory syncytial virus in young children with hemodynamically significant congenital heart disease. J Pediatr 2003;143:532-40.

103. Carbonell-Estrany X, Simoes EA, Dagan R, et al. Motavizumab for prophylaxis of respiratory syncytial virus in high-risk children: a noninferiority trial. Pediatrics 2010;125:e35-51. 104. O'Brien KL, Chandran A, Weatherholtz R, et al. Efficacy of motavizumab for the prevention of respiratory syncytial virus disease in healthy Native American infants: a phase 3 randomised doubleblind placebo-controlled trial. Lancet Infect Dis 2015;15:1398-408.

105. Feltes TF, Sondheimer HM, Tulloh RM, et al. A randomized controlled trial of motavizumab versus palivizumab for the prophylaxis of serious respiratory syncytial virus disease in children with hemodynamically significant congenital heart disease. Pediatr Res 2011;70:186-91.

106. Simoes EA, Groothuis JR, Carbonell-Estrany X, et al. Palivizumab prophylaxis, respiratory syncytial virus, and subsequent recurrent wheezing. J Pediatr 2007;151:34-42, e1.

107. Simoes EA, Carbonell-Estrany $\mathrm{X}$, Rieger $\mathrm{CH}$, et al. The effect of respiratory syncytial virus on subsequent recurrent wheezing in atopic and nonatopic children. J Allergy Clin Immunol 2010;126:25662.

108. Blanken MO, Rovers MM, Molenaar JM, et al. Respiratory syncytial virus and recurrent wheeze in healthy preterm infants. N Engl J Med 2013;368:1791-9.

109. Mejias A, Chavez-Bueno S, Rios AM, et al. Anti-respiratory syncytial virus (RSV) neutralizing antibody decreases lung inflammation, airway obstruction, and airway hyperresponsiveness in a murine RSV model. Antimicrob Agents Chemother 2004;48:1811-22.

110. Mejias A, Chavez-Bueno S, Rios AM, et al. Comparative effects of two neutralizing antirespiratory syncytial virus (RSV) monoclonal antibodies in the RSV murine model: time versus potency. Antimicrob Agents Chemother 2005;49:4700-7.

111. Mochizuki H, Kusuda S, Okada K, et al. Palivizumab Prophylaxis in Preterm Infants and Subsequent Recurrent Wheezing. Six-Year Follow-up Study. Am J Respir Crit Care Med 2017;196:29-38.

112. Mejias A, Garcia-Maurino C, Rodriguez-Fernandez R, Peeples ME, Ramilo O. Development and clinical applications of novel antibodies for prevention and treatment of respiratory syncytial virus infection. Vaccine 2017;35:496-502.

113. Kainulainen L, Vuorinen T, Rantakokko-Jalava K, Osterback R, Ruuskanen O. Recurrent and persistent respiratory tract viral infections in patients with primary hypogammaglobulinemia. J Allergy Clin Immunol 2010;126:120-6.

114. Rhinoviruses. In: Cherry JDH, Gail, Kaplan S, Steinbach W, Hotez P, eds. Feigin and Cherry's Textbook of Pediatric Infectious Diseases - 8th Edition: Elsevier; 2018.

115. Perkins JC, Tucker DN, Knopf HL, Wenzel RP, Kapikian AZ, Chanock RM. Comparison of protective effect of neutralizing antibody in serum and nasal secretions in experimental rhinovirus type 13 illness. American journal of epidemiology 1969;90:519-26.

116. Butler WT, Waldmann TA, Rossen RD, Douglas RG, Jr., Couch RB. Changes in IgA and IgG concentrations in nasal secretions prior to the appearance of antibody during viral respiratory infection in man. J Immunol 1970;105:584-91.

117. Levandowski RA, Ou DW, Jackson GG. Acute-phase decrease of T lymphocyte subsets in rhinovirus infection. J Infect Dis 1986;153:743-8. 
118. Jartti T, Paul-Anttila M, Lehtinen P, et al. Systemic T-helper and T-regulatory cell type cytokine responses in rhinovirus vs. respiratory syncytial virus induced early wheezing: an observational study. Respir Res 2009;10:85.

119. Estripeaut $D$, Torres JP, Somers CS, et al. Respiratory syncytial virus persistence in the lungs correlates with airway hyperreactivity in the mouse model. J Infect Dis 2008;198:1435-43.

120. Pinto RA, Arredondo SM, Bono MR, Gaggero AA, Diaz PV. T helper 1/T helper 2 cytokine imbalance in respiratory syncytial virus infection is associated with increased endogenous plasma cortisol. Pediatrics 2006;117:e878-86.

121. Bont L, Heijnen CJ, Kavelaars A, et al. Monocyte IL-10 production during respiratory syncytial virus bronchiolitis is associated with recurrent wheezing in a one-year follow-up study. Am J Respir Crit Care Med 2000;161:1518-23.

122. Aoyagi M, Shimojo N, Sekine K, Nishimuta T, Kohno Y. Respiratory syncytial virus infection suppresses IFN-gamma production of gammadelta T cells. Clin Exp Immunol 2003;131:312-7.

123. Knudson CJ, Varga SM. The relationship between respiratory syncytial virus and asthma. Vet Pathol 2015;52:97-106.

124. Mukherjee S, Lindell DM, Berlin AA, et al. IL-17-induced pulmonary pathogenesis during respiratory viral infection and exacerbation of allergic disease. Am J Pathol 2011;179:248-58.

125. Mangodt TC, Van Herck MA, Nullens S, et al. The role of Th17 and Treg responses in the pathogenesis of RSV infection. Pediatr Res 2015;78:483-91.

126. Bettelli E, Korn T, Kuchroo VK. Th17: the third member of the effector T cell trilogy. Curr Opin Immunol 2007;19:652-7.

127. Matsuzaki G, Umemura M. Interleukin-17 as an effector molecule of innate and acquired immunity against infections. Microbiol Immunol 2007;51:1139-47.

128. Wiehler S, Proud D. Interleukin-17A modulates human airway epithelial responses to human rhinovirus infection. Am J Physiol Lung Cell Mol Physiol 2007;293:L505-15.

129. Ramilo O, Mejias A. Respiratory Syncytial Virus-induced Acute Disease Severity and Long-Term Wheezing. Uncovering the Unexpected. Am J Respir Crit Care Med 2018;198:984-6.

130. Faber TE, Groen H, Welfing M, Jansen KJ, Bont LJ. Specific increase in local IL-17 production during recovery from primary RSV bronchiolitis. J Med Virol 2012;84:1084-8.

131. Durant LR, Makris S, Voorburg CM, Loebbermann J, Johansson C, Openshaw PJ. Regulatory T cells prevent Th2 immune responses and pulmonary eosinophilia during respiratory syncytial virus infection in mice. J Virol 2013;87:10946-54.

132. Martinez FD. Respiratory syncytial virus bronchiolitis and the pathogenesis of childhood asthma. Pediatr Infect Dis J 2003;22:S76-82.

133. Crotty S. T follicular helper cell differentiation, function, and roles in disease. Immunity 2014;41:529-42.

134. Bentebibel SE, Lopez S, Obermoser G, et al. Induction of ICOS+CXCR3+CXCR5+ TH cells correlates with antibody responses to influenza vaccination. Sci Transl Med 2013;5:176ra32.

135. Do LAH, Pellet J, van Doorn HR, et al. Host Transcription Profile in Nasal Epithelium and Whole Blood of Hospitalized Children Under 2 Years of Age With Respiratory Syncytial Virus Infection. J Infect Dis 2017;217:134-46.

136. Kollmann TR, Kampmann B, Mazmanian SK, Marchant A, Levy O. Protecting the Newborn and Young Infant from Infectious Diseases: Lessons from Immune Ontogeny. Immunity 2017;46:350-63.

137. Olin A, Henckel E, Chen Y, et al. Stereotypic Immune System Development in Newborn Children. Cell 2018;174:1277-92 e14.

138. Kollmann TR, Crabtree J, Rein-Weston A, et al. Neonatal innate TLR-mediated responses are distinct from those of adults. J Immunol 2009;183:7150-60. 
139. Pedraza-Sánchez S, Hise AG, Ramachandra L, Arechavaleta-Velasco F, King CL. Reduced frequency of a CD14+CD16+ monocyte subset with high Toll-like receptor 4 expression in cord blood compared to adult blood contributes to lipopolysaccharide hyporesponsiveness in newborns. Clin Vaccine Immunol 2013;20:962-71.

140. Restori KH, Srinivasa BT, Ward BJ, Fixman ED. Neonatal Immunity, Respiratory Virus Infections, and the Development of Asthma. Front Immunol 2018;9:1249.

141. Fjaerli H-O, Bukholm G, Krog A, Skjaeret C, Holden M, Nakstad B. Whole blood gene expression in infants with respiratory syncytial virus bronchiolitis. BMC Infect Dis 2006;6:175.

142. Mejias A, Dimo B, Suarez NM, et al. Whole blood gene expression profiles to assess pathogenesis and disease severity in infants with respiratory syncytial virus infection. PLoS Med 2013;10:e1001549.

143. Bucasas KL, Mian Al, Demmler-Harrison GJ, et al. Global gene expression profiling in infants with acute respiratory syncytial virus broncholitis demonstrates systemic activation of interferon signaling networks. Pediatr Infect Dis J 2013;32:e68-76.

144. Jong VL, Ahout IML, van den Ham H-J, et al. Transcriptome assists prognosis of disease severity in respiratory syncytial virus infected infants. Sci Rep 2016;6:36603.

145. Chaussabel D, Baldwin N. Democratizing systems immunology with modular transcriptional repertoire analyses. Nat Rev Immunol 2014;14:271-80.

146. Heinonen S, Jartti T, Garcia C, et al. Rhinovirus Detection in Symptomatic and Asymptomatic Children: Value of Host Transcriptome Analysis. Am J Respir Crit Care Med 2016;193:772-82. 


\section{FIGURE LEGENDS}

Figure 1. Age at the time of infection influences the host immune response to respiratory syncytial virus (RSV) and rhinovirus (RV) infection. (A) RSV immune response according to age. The upper panel shows the modular analyses performed and compared between 20 infants $<6$ months of age with RSV lower respiratory tract infection (LRTI), and 17 children with RSV LRTI 624 months of age ${ }^{44,145}$. Both groups had similar clinical disease severity scores (CDSS). Healthy, age-matched controls, 9 per group, were used as a reference. Colored spots represent the percentage of significantly over-expressed (red) or under-expressed (blue) transcripts within a module in patients with RSV infection compared to controls, and the number included in the dots are the percentage of over or underexpressed transcripts. Blank modules demonstrate no significant differences between patients and controls. The middle panel summarizes the percentage of over and underexpressed transcripts according to the two age groups and in relation to the overall RSV signature. Infants less than 6 months of age with RSV LRTI displayed a greater number of underexpressed transcripts (64\%) as compared with those 6-24 months of age (29\%). The lower panel further illustrated in a spider graph format representing the permodule median expression values of the significant different modules between the two age groups. (B) Modular analysis in children with RV LRTI (less than 6 months; $n=12$ and 8 matched controls and 6-24 months: $n=8$ and 6 controls) revealed fewer differences in host responses according to age. Horizontal bars illustrate the proportion of over- and under-expressed modules in infants (less than 6 months) and children 6-24 months of age in relation to the global influenza and RV signature. These differences are further illustrated in a spider graph format representing the per-module median expression values of the significant different modules between the two age groups. 


\section{FIGURES}

\section{Figure 1.}

\section{A. RSV}
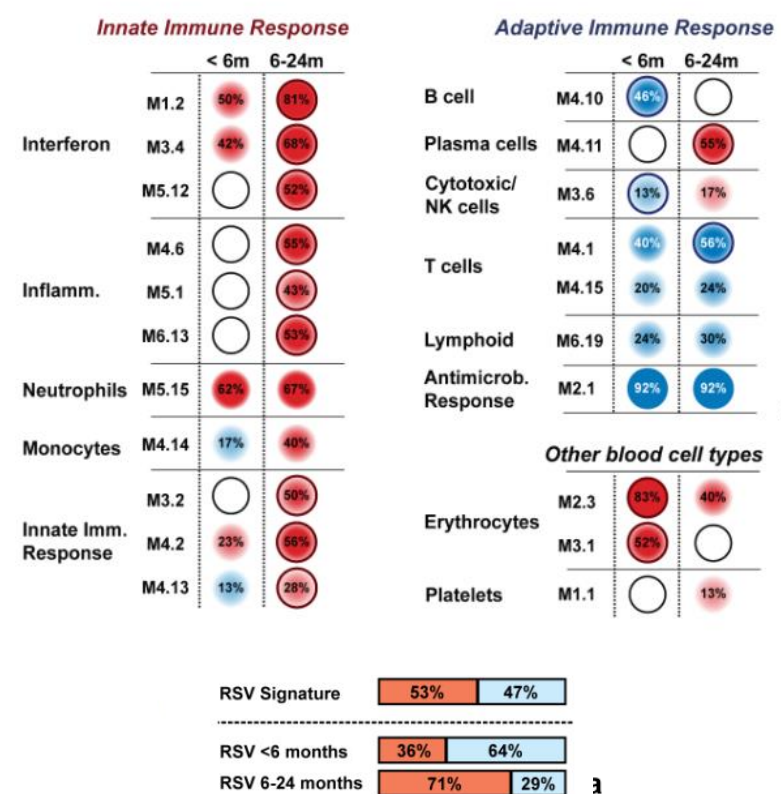

$\square$ Modules Over expressed (\%)

$\square$ Modules Under expressed (\%)

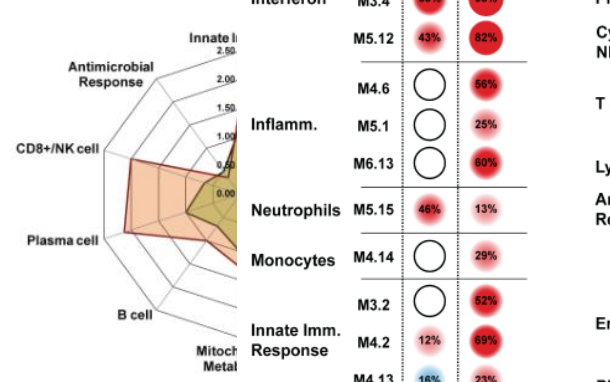

\section{B. Rhinovirus}

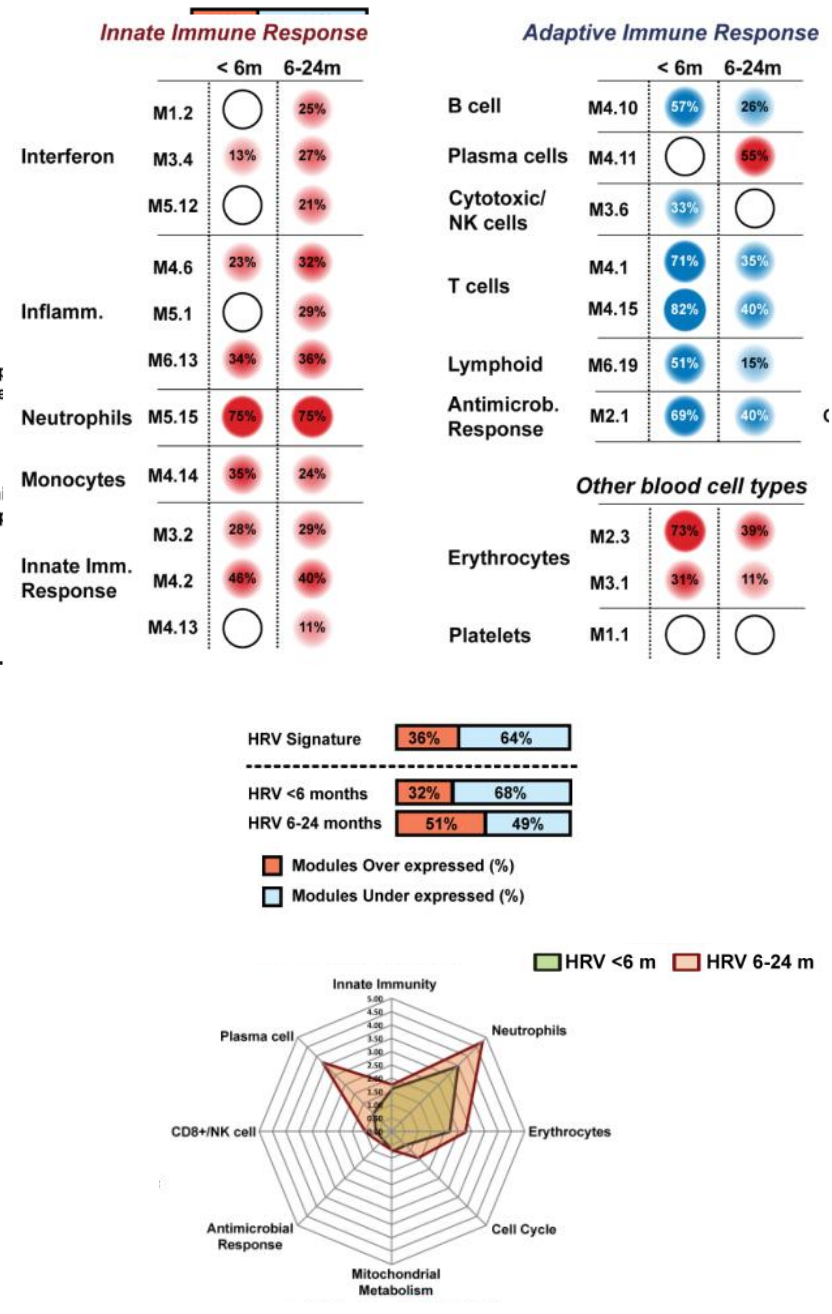

